\title{
Theorizing Hybrid Models of Peer Production: A Case Study of an Open Collaborative Journalism Platform
}

\author{
Sheila O'Riordan \\ Business Info. Systems \\ University College Cork \\ sheila.oriordan@ucc.ie
}

\author{
Gaye Kiely \\ Business Info. Systems \\ University College Cork \\ gaye.kiely@ucc.ie
}

\author{
Bill Emerson \\ Business Info. Systems \\ University College Cork \\ b.emerson@ucc.ie
}

\author{
Joseph Feller \\ Business Info. Systems \\ University College Cork \\ jfeller@ucc.ie
}

\begin{abstract}
Peer production communities (c.f. Benkler 2002) are typified by principles of access to resources, inclusive participation, transparency of action, and democratic work. However, the ways in which they operate and evolve depend on various infrastructural and governance mechanisms. Literature suggests that there are three key challenges to overcome in building and sustaining a community that produces open knowledge goods, namely motivation (incentives for participation), coordination (efficient organization of work), and integration (effective creation of high quality end products). We present a theoretical framework to analyze case study findings from the WikiTribune project, a "hybrid" model of peer production. This project is characterized as an open collaborative journalism model that combines elements of commercial firm-based production with that of commons-based peer production. The framework identifies factors affecting hybrid models and the impact on community and resource development.
\end{abstract}

\section{Introduction}

WikiTribune is an evidence-based collaborative journalism project that centers on the development of a diverse and culturally-dependent knowledge artifact: news articles. WikiTribune exhibits characteristics similar to open source software (OSS) communities and other peer production communities like Wikipedia (both founded by Jimmy Wales). WikiTribune is in the early stages of its lifecycle (launched October 2017), however the concept of collaboratively producing evidence-based news is a rising phenomenon in a media landscape transformed by digital technologies $[1,8]$. This paper presents a case study of WikiTribune as an emerging platform and community that combines characteristics of different types of open peer production models to solve an ongoing media challenge; to provide evidence and fact-based news
$[15,20,27]$. Implementing a "hybrid" model, WikiTribune combines the work of paid staff members (e.g. professional journalists; community managers; software developers) with a global distributed volunteer community (anyone can join, contribute, and access the content). The model arguably represents a shift towards more mainstream adoption of peer production, similar to the transformation within OSS from its ideological roots to widespread commercial viability $[10,11]$. It also suggests an evolution from the Wikipedia "consensus over credentials" model [31] and alternative approaches to addressing concerns of accuracy and reliability in the quality of content produced. WikiTribune, in its own words "takes professional, standards-based journalism and incorporates the radical idea from the world of Wiki that a community of volunteers can and will reliably protect and improve articles" ${ }^{\prime}$. As a result, tensions may exist between volunteerism and professionalism that may influence the project and its development and the way volunteers and staff participate [17]. This unique element adds further complexity to a model of production that has transformed society and the economy [3]. It is this hybrid aspect of WikiTribune and the interplay between professional community members and the volunteers who join that will be under examination. The objective of this study is to theorize the impacts of a hybrid model of peer production on content and community development. To do this, the paper first conceptualizes WikiTribune's model of production to illustrate its current resources, processes, and project context (Section 2). Next, the model is theorized (Section 3) building on Benkler's [3] theorization of commonsbased peer production, which identifies both advantages and challenges within this mode of production and mechanisms that potentially affect community outcomes. We then present the study's methodology, findings, discussion and conclusions (Sections 4-7).

${ }_{1}^{1}$ web.archive.org/web/20170426025452/https://www.wikitribune.co $\mathrm{m} /$ 


\section{Characterizing WikiTribune's Model}

In this paper, we characterize WikiTribune and its hybrid model of production by applying the concept of "openness". Openness is a paradigm defined by principles of access, participation, transparency, and democracy, or more specifically: the accessibility of information and other resources, inclusive and often collaborative participation, transparency of resources and actions, and the "democratization" of work (e.g. breaking up exclusionary structures) [26:299]. In this framing of openness, Schlagwien et al. [26] set forth examples of open phenomena ranging from those related to open resources like open APIs, open content, open data, and open source code, to open processes found in crowdsourcing, open source development, open innovation and idea contests. In addition, a third grouping of open phenomena relate to those under which opening effects occur within specific domains, including: open business, open education, open government, and open science. We assert all three aspects are important in understanding WikiTribune: (1) the open nature of resources, (2) the open nature of processes, and (3) the open context in which the community operates (i.e. journalism).

WikiTribune shares characteristics with other production communities like GitHub (a digital workspace for the production of software and nonsoftware digital artifacts [5, 24]) and Wikipedia (a non-profit wiki-based global encyclopedia), however, the way in which the various open principles manifest and are enacted differ across projects. We consider WikiTribune a "hybrid" model because it is a for-profit organization that hires and manages paid professionals to produce content (unlike GitHub and Wikipedia), but also opens up the production of its product to anyone that wants to join and the consumption of its product to anyone that visits the website (unlike more traditional organizations). WikiTribune's open resources include open APIs and an open source content management system, open content using Creative Commons licensing, and open data that is accessible and shareable. The open processes in WikiTribune can be compared with those used in crowdsourcing (e.g. leveraging a large group of individuals in the pursuit of a common goal [9]), open source development (e.g. hierarchy of rights based on experience and skillset; professional versus amateur [4]), and open innovation (e.g. internal and external knowledge flows with both inside-out and outside-in open innovation strategies $[12,21])$. Thus, WikiTribune's organization includes both professionalism and volunteerism, which both have a distinctive way for controlling and organizing work and its workers [17].
In addition, WikiTribune is a "collaborative journalism" project operating within the news and media domain. Projects like GitHub, in contrast, are software development communities with non-wiki features that have evolved to produce text artifacts like books and policy statements [24]. But the news domain and the production of news articles provides its own unique context and potential opening effects. For example, over the last few decades, journalism has seen a rise in participatory practices $[6,30]$ and interactive social technologies [1, 14]. Vobic and Dahlgren [30:17] note that "the situation of online journalism today is difficult to grasp in its totality. This sprawling domain is comprised of mainstream online media, together with the various types of participatory journalism." The term "participatory journalism" here is used as a catch-all for all forms of non-professional activities that capture the collaborative and collective action taking place in journalism. However, there are often no clear and set distinctions between the types of journalism set forth in the literature. Many of the categories and characteristics of journalism overlap, with people and technology shaping the change as well as ongoing discussions between interdisciplinary researchers [16]. To clarify some of these concepts, Nip [22] characterized five models of journalism using the level of audience participation as a lens: (1) traditional journalism, (2) public (or civic) journalism, (3) interactive journalism, (4) participatory journalism, and (5) citizen journalism. These models help illustrate where, in the publication lifecycle, the audience is included (see Figure 1) and to better understand WikiTribune's model of journalism from the literature.

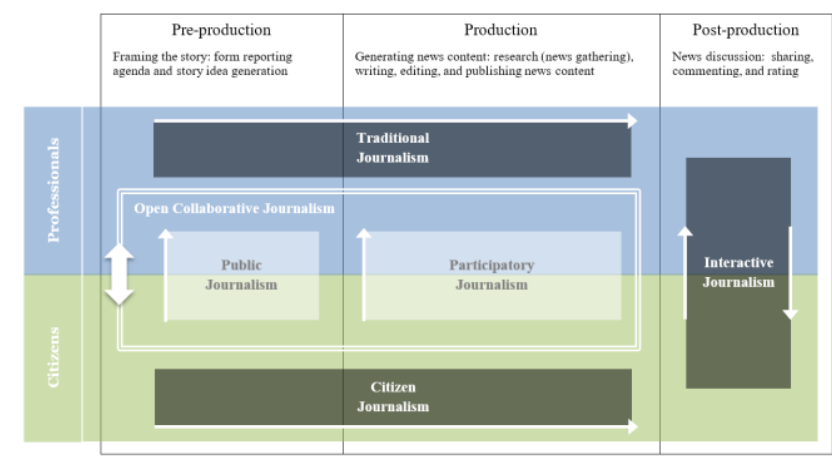

Figure 1. Representation of journalism models

In traditional journalism citizens have a very limited role in the early stages of production, mainly as a source for professional journalists. It is in postpublication that citizens become the audience and consume the news content. Alternatively, public (or civic) journalism engages the public in the early stages of story development to help form the reporting agenda through town hall meetings or public polls. Interactive 
journalism contrasts with the other models, in that it often relates to post-publication interactions between the public and professionals (e.g. online discussions in a published news article's comment section or social media post). This interactivity can be used in conjunction with all of the other models, and is possible because of the advancement in digital social technologies and the evolution of "news as conversation" [13]. Participatory journalism, according to Nip, should not be confused with citizen journalism. Participatory journalism is still controlled by the professionals but opens up some of the news gathering and content generation to the public by including them in the pre-publication process. Citizen journalism is the antithesis of traditional journalism, whereby the professional is removed from the process and the public is in control of the entire lifecycle. These distinctions are yet to be accepted across the literature, and it is difficult to unravel some of the overlapping concepts and practices.

However, these concepts can be used as a framing tool for understanding the term "collaborative journalism" which is how WikiTribune describes itself. To investigate this term and to place it within or beyond the five models of journalism, we searched ten databases for the key phrase "collaborative journalism" within titles, abstracts, or keywords (limited to journal articles and conference papers). Seven databases (AIS e-library, EBSCO Business Source Complete, IEEE Xplore, JSTOR, Science Direct, SpringerLink, and Wiley Online Library) returned no results but three of the databases (EBSCO Academic Source Complete, Scopus, and Web of Science) returned 22 papers. Removing articles that were duplicates, false positives, or insufficiently relevant yielded 6 articles (three fulllength and three abstracts) directly related to the concept or phenomenon of "collaborative journalism".

Three themes were identified in these articles. Firstly, collaborative journalism is presented as professional and non-professional collaborations in the production of news content $[7,13,28]$. In this context, the journalists maintain their role as gatekeepers and control the environment in which the collaboration is conducted (can be categorized as a subset of participatory journalism). Secondly, collaborative journalism was presented as collaborations between different organizations or groups. In this context, data journalism and municipal journalism inform the definition [23, 29]. In this set of papers, groups such as data scientists, researchers, or government officials interact and collaborate with journalists to create news content (can also be aligned with the participatory journalism model). Finally, one research paper refers to collaborative journalism as open source editing [18]. This theme fits with the WikiTribune project and details an investigation into a similar project: Wikinews. However, Wikinews does not include professional journalists in their model and is more in line with the use of wiki technology in a citizen journalism model.

Thus, the term collaborative journalism in the literature often relates to the various collaborative practices taking place within the different models of journalism. In participatory journalism, professional journalists retain their status as the gatekeeper, but are open to collaborations with amateurs or other groups to co-create news content. For citizen journalism, the public co-create news content independently of professional pressures or boundaries. WikiTribune is somewhere between this participatory model of journalism that includes professionals, and the citizen model of journalism, which opens up all activities and control in the pre-publication lifecycle to the public.

In this study we use the term "Open Collaborative Journalism" (OCJ) to combine elements of both participatory and citizen models of journalism while extending the boundaries of each. We define OCJ as: collaboratively producing news content using open and democratic principles by both professionals and nonprofessionals in the news production lifecycle. OCJ is set in the context of openness, functioning in ways similar to GitHub, Wikipedia and other open production domains. It is an open participatory model of production where the role of the audience has shifted from passive consumer to active co-producer and where professional journalists, while still included, are no longer the sole actors setting the reporting agenda or in full control of the publication process. Thus, professionals work alongside citizens as equals and participation is inclusive and self-determined.

\section{Theoretical Foundation}

WikiTribune represents a new type of open production given its hybrid nature and as an example of OCJ (combining characteristics of various models of journalism). Similar to the professionalization of OSS and its integration with mainstream commercial models [10, 11], WikiTribune combines elements of firm-based production (managerial hierarchies and topdown structures) with that of commons-based peer production (CBPP) [3]. A central characterization of CBPP is that "groups collaborate on large-scale projects following a diverse cluster of motivational drives and social signals, rather than either market prices or managerial commands" [3:2]. In WikiTribune professional journalists are hired as a part of this process, who indeed work within a managerial structure. This model may or may not fully benefit 
from the advantages associated with CBPP. We propose the application of the framework by Benkler [3] to help understand the project's socially productive behavior and the dynamics and factors influencing their manifestations.

To begin with, CBPP represents a distinct mode of production enabled by a digitally networked environment. Benkler asserts that this mode of production has advantages over markets and managerial hierarchies when the object of production is information or cultural and the physical capital (e.g. computers and communication capabilities) is widely distributed. This model relies on decentralized information gathering and exchange, which helps in reducing participant uncertainty and as a result benefits from a particular advantage in identifying and allocating resources (i.e. assigning human capital to production processes) as well as in identifying the opportunities for such collaborations (i.e. allocation efficiency) [3]. Benkler refers to these advantages as the (1) information processing advantage (IPA) and the (2) resource allocation advantage (RAA). These advantages leverage individual self-awareness and selfselection of tasks, and a large pool of resources in conjunction with a larger pool of diverse agents, enhancing the likelihood of matching appropriate tasks with a skilled agent. These advantages are useful in the context of information and cultural products, as human creativity is the most critical and expensive resource in its production (given the low barriers to entry in digitally networked environments). However, Benkler goes on to outline three challenges that occur in this mode of production, namely the (1) motivation challenge (MC), (2) coordination challenge (CC), and (3) integration challenge (IC). The motivation challenge exists because it is necessary to provide incentives (whether monetary or non-monetary) for people to participate in the project when no exclusive proprietary control over the final product is assured. The coordination and integration challenges arise due to a lack of power to formally organize the collaboration in the use of the resource.

To address these challenges, projects are encouraged to be modular in nature, so that people can work on individual units of the project simultaneously. While also allowing for each module to be granular and heterogeneous, or in other words, to be broken down into different types and various sized tasks that require different skill-levels or time commitments. In becoming modular, fine-grained, and heterogeneous, "the motivation necessary to get any given individual to contribute need only be very small" and this creates an advantageous environment whereby work is "incremental and asynchronous, pooling the efforts of different people, with different capabilities, who are available at different times" [3:10]. As such, people who range in background and levels of experience can decide to commit varied amounts of time and effort to a project [27]. A part of this is reducing uncertainty, whether through signals to users or the information gains as a result of a large highly variable and individuated contributor base [3]. In general, outside of financial incentives, people will participate based on reputation gains, experience gains (i.e. increases in human capital) or even just for fun. A sustainability issue arises if the motivation challenge is not met. This has been described as the startup paradox; whereby a critical mass of active members is required in the initial project phases to generate enough content to both attract new members and sustainably grow the community over time [25, 33]. This can affect the health of a community in the long term. Unfortunately, due to the nature of these projects, they are prone to consumer and producer volatility [19]. For example, high accessibility conditions enable sudden growth in community and content necessary for achieving critical mass, but by the same token are vulnerable to the sudden exit of content producers and subsequent collapse of a community.

Finally, in becoming modular, fine-grained, and heterogeneous, some of the motivation and coordination challenges can be overcome. However, this leaves the integration challenge and creating a cohesive whole with a high quality final product. Lowcost integration can be achieved through module quality control (to defend against incompetent or malicious contributions) and mechanisms for integrating the contributions into a finished product (automated integration or iterative peer production). In order to control module quality the following measures can be implemented: formal rules, technical constraints, social norms, and mechanisms for addressing redundancy of contributions and averaging out of outliers [3]. As such, there are a number of ways integration can be organized, which depend on technological and community governance factors.

\section{Methodology}

This single "extreme" case study [32] focuses on the unique circumstances of the project within an 18month timeframe, between May 2017 and November 2018 and three distinct phases of WikiTribune's (henceforth WT) community and platform development. This time frame allows us to adjust for community growth and to identify effects of change in community size, policies, or platform redesigns. The three six-month periods include: (1) pre-launch (May17 to Nov-17); (2) version-1 (V1) pilot launch (Nov-17 
to May-18); and (2) version-2 (V2) platform redesign (May-18 to Nov-18). Qualitative data was collected from multiple sources including: focused searches on Internet archive "wayback machine" to examine evolution of the platform across each time period, official WT e-mails $(n=107)$ from point of researcher registration (March 2018), WT Slack analytics data (alternative public communication platform) for total members and daily active users, and specific searches for WT project posts or user profiles (across official channels) to identify project relevant information. In addition, quantitative metric data was collected on the complete sample of WT articles $(n=1597)$ including data on article authors, number of categories (i.e. formal project-assigned taxonomy of topics) and tags (i.e. informal user-generated topics), and number of talk comments. During this time period, 46 staff members were identified through user profiles on the WT platform and Slack workspace. Identifying the roles within online communities is essential for understanding quality assurance, coordination, and conflict resolution processes [2]. Thus, we compare participation and contribution levels of paid professionals and unpaid volunteers across the project lifecycle and identify the factors related to motivation, coordination, and integration from the sources of evidence above.

\section{Findings}

WikiTribune had a total of 1597 articles from May 2017 to the end of October 2018 (151 of which were drafts). Figure 2 displays these articles across each time period (excluding period 2, June 2017, which had zero articles). This figure identifies the breakdown between staff creators, volunteer creators, and deleted users. In addition, the growth of unique authors for each month is presented. Overall, there were 204 unique article creators identified in the data set. During this time, the size of the community on Slack went from 178 by the end of October 2017 (pre-launch) to 477 by the end of April 2018 (V1), and 558 by the end of October 2018 (V2). In those periods an average of 10 unique authors $(5.6 \%$ of total Slack members at that time) created articles each month pre-launch (25 total unique authors overall). This grew to 26 (5.5\% of Slack members) during V1 (85 total unique authors overall), and 38 (6.8\% of Slack members) during V2 (140 total unique authors overall). Staff were more likely to start an article from scratch, accounting for $72 \%$ (or 1146) of all articles. Volunteers created $26 \%$ (or 421) of all articles, with the remainder attributed to deleted user accounts. This dynamic began to shift in the V2 platform redesign period, with increasing numbers of articles created by volunteers, and then a significant drop in the final month by staff creators and overall production levels.

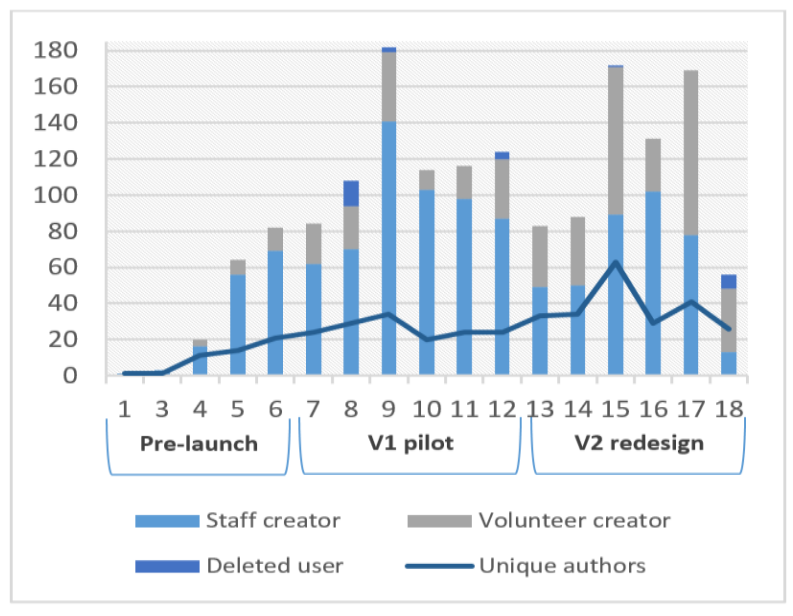

Figure 2. Total articles by role with unique article creators $(n=1597)$

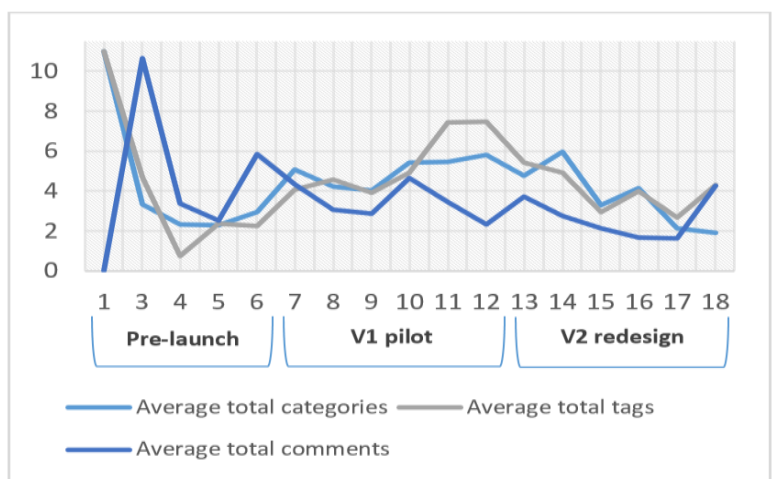

Figure 3. Average total categories, tags, and comments $(n=1597)$

Figure 3 shows the rise and fall of average total categories, tags, and comments associated with each period. Comments begin to taper near the end of the time period with a positive upswing in the final month, perhaps representing reengagement. The categories (formalized) and tags (user-generated) show an increase of topic coverage in the mid-range phase of the project, but a fall in coverage nearing the end of the timeline possibly attributed to the increase in volunteer created articles and unique number of authors, who may or may not be categorizing articles appropriately, or else possible indicating homogeneity in article focus.

\subsection{Pre-launch period (May-17 to Nov-17)}

This period is characterized by a focus on professional journalists and editorial staff and their 
future role in the community, while also promoting a message to encourage participation and community involvement once the platform is launched. The platform is not yet public and only limited community members have access to the beta site for testing purposes (from mid-September 2017). Some factors impacting motivation include the support provided from over 12,000 donors and other organizations that committed funds toward project development. These donors represent potential community members that have already committed time and money toward the initiation of the project, whether as future producers or consumers. Monetary incentives are limited to the professional editorial staff. Factors affecting coordination of the community include the hiring of the launch editor (August 2017) in charge of managing the professional journalists and the daily news agenda. In addition, an alternative public communication channel is created (i.e. the Slack workspace) in June 2017 to discuss the project and ideas for news articles. This is in combination with "project" posts (separate from news articles) on the platform and e-mail newsletters, which contain article highlights and information on the news agenda.

5.1.1. Pre-launch framework. Applying the theoretical framework to the data, Table 1 summarizes the factors related to the advantages during the prelaunch period and the potential challenges in terms of motivation (MC), coordination (CC), and integration (IC). This is a period of development (both content and

\section{Table 1. Summary of pre-launch factors}

\begin{tabular}{c|l}
\hline & $\begin{array}{l}\text { Large group of motivated donors supporting the } \\
\text { project as potential producers/consumers. }\end{array}$ \\
Small group of skilled professional staff with relevant \\
experience for creating news content. \\
\hline \multirow{3}{*}{$\begin{array}{l}\text { WT staff setting news agenda affording a top-down } \\
\text { form of granularity for task setting. } \\
\text { Modular news articles that can be created } \\
\text { independently (but not built collaboratively). }\end{array}$} \\
\hline \hline & $\begin{array}{l}\text { Limited contributor-base some volunteers included in } \\
\text { beta testing of platform. } \\
\text { Lack of diversity small limited paid staff members in } \\
\text { community. } \\
\text { Not heterogeneous news agenda set and controlled by } \\
\text { editorial team with focus on current affairs. }\end{array}$ \\
\hline & $\begin{array}{l}\text { Isolated article creation with limited collaborative } \\
\text { capabilities. } \\
\text { Limited resources with focus on developing content to } \\
\text { attract users on launch. } \\
\text { Managerial hierarchy with insular communication } \\
\text { through formal channels. }\end{array}$ \\
\hline & $\begin{array}{l}\text { Private beta platform with limited users/content to } \\
\text { integrate articles and work. } \\
\text { Internal formalization of processes and social } \\
\text { structures to improve integration and quality. }\end{array}$ \\
\hline
\end{tabular}

technical platform), with a core set of paid professionals developing content to begin creating value and attracting users. We describe this stage as having: (1) a limited community (of professional staff and project donors), (2) a platform under development, and (3) a managerial hierarchy. Both the project resources and processes are closed in nature, and neither accessible nor transparent to a broader community as of yet.

\subsection{V1 pilot launch (Nov-17 to May-18)}

The pilot project was launched to the public at the end of October 2018. During this period of growth, people began to register and participate in a variety of ways, whether through commenting, article creation, or revisions. We see the highest peak in article production in the second month of this period (9 in Figure 2). But over time, and in subsequent months, participation levels began to drop, and the staff remained as the majority producers of content. In fact, 10 editorial staff members represented the top 10 article creators overall (4.9\% of unique article authors), creating $62 \%$ of all articles and between 44 and 140 articles each. New volunteers did not share the same permissions as staff members and were unable to set an article to a published status. The professionals act as gatekeepers deciding what qualifies an article as ready to be published. The design of the platform centers on readability over edit-ability, with a number of grids and sections highlighting specific articles (see Figure 4), akin to an online commercial newspaper.

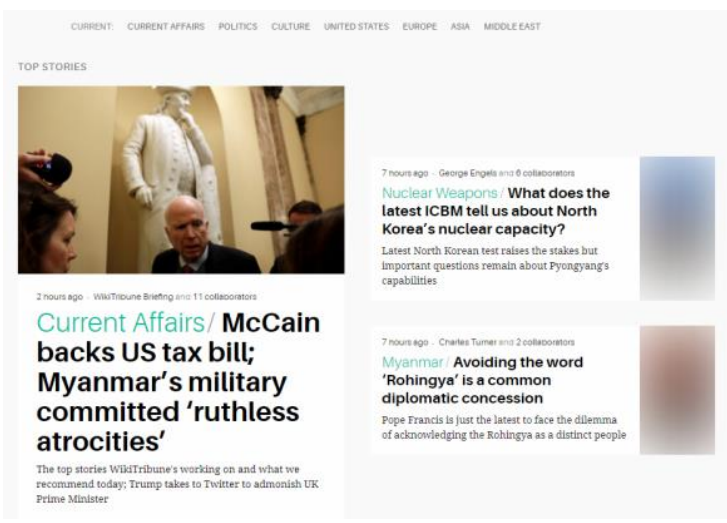

Figure 4. WT home page (November 2017)

In addition, there are seven core topics included on the home page. These topics are: Current Affairs, Politics, Culture, United States, Europe, Asia, and Middle East. Hence a lack of heterogeneity to leverage the resource allocation and information processing advantages of larger communities. It is near the end of this period that certain updates to the project are being announced. For example, in April 2018, the launch 
editor leaves the project (April 2018) with a fall in production in subsequent periods (13 and 14 in Figure $2)$, there are ongoing staffing changes, and they begin crowdfunding to expand WikiTribune into Spanish (expanding into more cultures and demographics). In addition, certain community-driven initiatives are underway, including the formalization of a fact checking space to organize and coordinate related projects. Fact checking is recognized as valuable work that can be addressed by the WT model and the capabilities of a large community. This represents a more formulaic and accessible task for amateur contributors, and less complex than creating a new article.

5.2.1. V1 framework. Applying the theoretical framework to the data, Table 2 summarizes the factors related to the advantages in this period and the potential factors related to emerging challenges. This is a period of growth in both community and content with an open call for the public to register and join the

\section{Table 2. Summary of V1 factors}

\begin{tabular}{|c|c|}
\hline 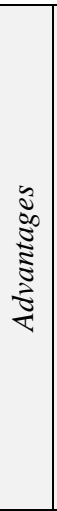 & $\begin{array}{l}\text { Expanded community of volunteers joining platform } \\
\text { and formal channels; with more diverse community } \\
\text { base (different skills, experiences, and availability) and } \\
\text { more heterogeneity (through expanded resources and } \\
\text { topic taxonomy). } \\
\text { Modular news articles that can be collaboratively built } \\
\text { via new platform (increased accessibility) and self- } \\
\text { selected by community of users. } \\
\text { Use of multiple channels of communication to reach a } \\
\text { wider audience and create relevant spaces for accessing } \\
\text { resources (WT talk pages, WT project posts, Slack } \\
\text { workspace, and others). } \\
\text { Formalization of spaces for accessing and discussing } \\
\text { projects and topics. }\end{array}$ \\
\hline 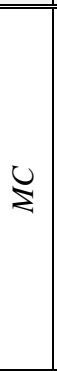 & $\begin{array}{l}\text { Unequal incentives of community members (paid staff } \\
\text { and unpaid volunteers). } \\
\text { "Read" design of website limiting participation } \\
\text { signals to users and accessibility of resources. } \\
\text { Required registration barrier to users (real names } \\
\text { encouraged) before being allowed to contribute. } \\
\text { Limited heterogeneity core of articles still created by } \\
\text { staff members and agenda set by editorial team. } \\
\text { Limited granularity of work which requires skill and } \\
\text { experience for greenfield production. }\end{array}$ \\
\hline$\circlearrowright$ & $\begin{array}{l}\text { Unequal power of community members } \\
\text { (administrative and publishing rights). } \\
\text { Expanded contributor base with which to coordinate } \\
\text { and communicate work. } \\
\text { Fragmented coordination through multiple channels } \\
\text { of communication with dispersed messages. } \\
\text { Limited filtering of article topics and projects to create } \\
\text { modular spaces to allocate resources. }\end{array}$ \\
\hline$\smile$ & $\begin{array}{l}\text { Limited formalization of processes and social } \\
\text { structures to improve integration and quality. }\end{array}$ \\
\hline
\end{tabular}

project. The way the community operates is still in flux with many issues remaining open to interpretation and the first step towards formalizing some processes and community policies under way. We describe this stage as having: (1) an expanded community including paid staff and unpaid volunteers, (2) a platform with a "read" design and limited taxonomy of topics, and (3) a social structure of restricted community rights with limited resources for new volunteers.

\subsection{V2 platform redesign (May-18 to Nov-18)}

The final phase represents a time of change and improvement for the WT platform and community of volunteers. A "radical redesign" to make the site "more wiki" is launched at the end of May 2018 with an official e-mail sent out to community members (see Figure 5). The project posted initial results from this redesign to the community in June 2018 with an increase in social actions, engagement, and visits (see 15 to 17 in Figure 2). However, the project is losing money and further redesigns are planned.

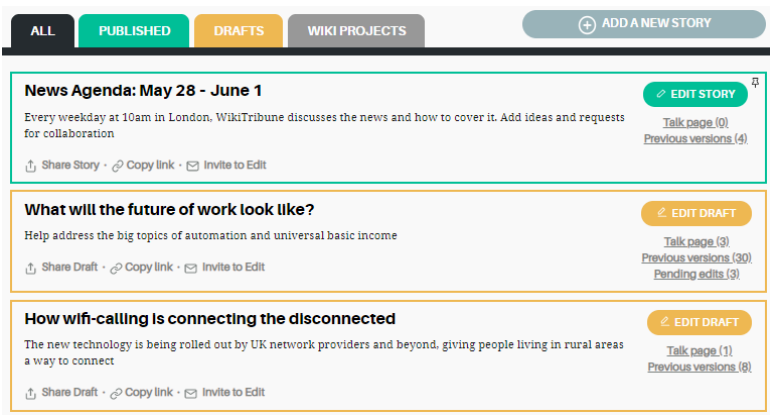

Figure 5. WT home page (May 2018)

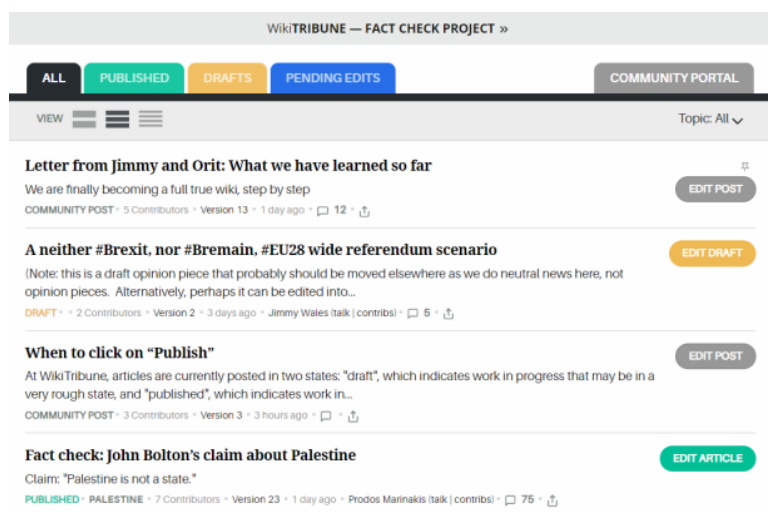

Figure 6. WT home page (October 2018)

The following updates occur in this period: in June 2018 the homepage algorithm is updated (to strike a balance between freshness and quality and better organize the articles for visitors and members); in July 2018 a new front-end editor is featured (to move away 
from the WordPress editor and make it easier to collaborate and contribute, also better for mobile devices); in September 2018 WikiTribune en Español is launched as a distinct platform, and a WT style guide is posted for the community (includes a collection of style resources and a guide to building stories).

At the end of this period (October 2018), a large number of changes are implemented. Firstly, user permissions for article publishing rights are updated (now trusted members and not just professional staff) to speed up the publishing process (evidence of bottlenecks and volunteer created articles remaining as drafts) as well as promote inclusivity and improve participation levels. There are also a number of staffing changes, with staff journalists laid off at the end of the period with an aim to hire new journalists refocused on community support (see drop in production in period 18 in Figure 2). An excerpt from the announcement explains: "We are still working through the site and finding vestiges of the clearly wrong perception that the journalists are 'above' the community, supervising their work. This was never the intention and it is something we got wrong in the early design. Despite the best efforts of staff, the overall structure and design didn't let the community genuinely flourish." With this change the community moves from Slack to Discord (members dropped from 558 to 329 in changeover).

Finally, a number of features are added to the platform, including: article history log improvements (distinguishing system actions from revision edits), a follow article button to receive notifications and updates about specific articles, a new community portal to create a space for community-driven initiatives and projects, and finally, a fact checking portal (as a space for all fact checking projects and articles). A number of these changes are visible in the screen shot of the home page in Figure 6. The prelaunch and V1 periods encouraged staff to create as many articles as possible and create a large number of resources. This was an advantage of the hybrid model, by having a core set of paid skilled staff members with planned time commitments for which to advance the community. But this advantage turned into a disadvantage by focusing efforts on the professionals and creating perceptions about their elevated role in the community. Member asymmetries evolved and implicit divisions between the role of the paid professional and the unpaid volunteer emerged. A factor influencing this was the lack of trust in allowing volunteers to publish articles - creating bottlenecks in production and discouraging certain tasks (i.e. quality checks) that actually may have benefitted from a large user base and a very defined and granular work task.
5.3.1 V2 framework. Applying the theoretical framework to the data, Table 3 summarizes the factors related to both the advantages and challenges identified during V2 project redesign. This is a period of improvement to address issues that have arisen during the launch and development of the pilot project. We describe this stage as: (1) a community in flux with increasing unpaid volunteers and ultimately the removal of the professionals, (2) a platform with a "write" design and expanded taxonomy of topics and filtering mechanisms, and (3) a social structure of expanded community rights and a growing number of resources for new and existing community members.

\section{Table 3. Summary of V2 factors}

\begin{tabular}{c|l}
\hline & $\begin{array}{l}\text { Growing community of unique authors joining } \\
\text { platform and formal channels (increased diversity) } \\
\text { Large pool of modular news articles with more } \\
\text { transparent and detailed revision histories. }\end{array}$ \\
Increased accessibility of resources and spaces for \\
coordination with new system features. \\
Levelling of incentives between community members \\
with less visible distinctions between paid and unpaid \\
staff (culminating in removal of paid journalists). \\
"Write" design of website increasing participation \\
signals to users and making resources accessible. \\
More defined production processes through project \\
policy and guideline developments
\end{tabular}

\section{Discussion}

Building on Benkler [3], we presented an analysis of a hybrid model of production and open collaborative journalism project using the concepts of resource allocation and information processing advantages, and motivation, coordination, and integration challenges. Aspects that disadvantaged the WikiTribune project and impacted on levels of participation and production stem from the hybrid model, as well as issues related to governance, via member asymmetries, power structures, and managerial hierarchies, as well as the technical infrastructure, including the "read" design of the platform and limited resource accessibility of the 
developed solution. Each phase of community development has a unique set of characteristics ranging from closed, hybrid, to more open modes of production; as noted in the evidence of progression from pre-launch to pilot launch and finally with the complete project redesign. For each of these representations certain advantages and challenges arise. As one challenge is met another subsequent challenge transpires with new community dynamics and manifestations. Building on Benkler's framework, we theorize that each of these design choices, or factors from the findings, produces a signal to the user that helps to reduce uncertainty for users and begins the process of leveraging the resource allocation and information processing advantages (see Table 4).

However, these signals also have potential consequences that may or may not benefit the project given the stage in the project lifecycle or given a particular set of project goals (i.e. increasing participation versus improving content quality). These signals need to be understood in order to pre-emptively tackle each challenge as it arises and at a point appropriate to the stage of community and platform development. These factors may help to reduce uncertainty in commons-based peer production, but their consequences are important to consider when making decisions about community operations. As stated, the stage of the project lifecycle needs to be taken into account to aid decision making and select the most appropriate governance and social structures. With each signal arising from the different modes of production, the resultant challenges must be addressed through policy formation, platform design choices, and visibility of production process information. Some of these signals may not benefit a large and open peer production community as the consequences may deter participation during a time when participation signals are key to community development and in reaching a critical mass of users. Some of the signals reducing uncertainty may benefit smaller more focused communities (open or closed) or communities at a more mature and stable stage of development.

Table 4. Signals and consequences

\begin{tabular}{lll} 
Signals & Reduction in uncertainty & Potential consequences \\
\hline User registration & $\begin{array}{l}\text { Users make a commitment and become part of a } \\
\text { team; more transparent, credible, and traceable }\end{array}$ & $\begin{array}{l}\text { Users need to want to commit to project, limits } \\
\text { ease of access and reduces opportunistic edits }\end{array}$ \\
\hline $\begin{array}{l}\text { Skilled } \\
\text { professionals }\end{array}$ & $\begin{array}{l}\text { Standards-based and skilled work, credible and } \\
\text { reliable content creation }\end{array}$ & $\begin{array}{l}\text { Division in skillset for amateur contributors; } \\
\text { divided members and task inequality }\end{array}$ \\
\hline $\begin{array}{l}\text { Unequal user } \\
\text { rewards }\end{array}$ & $\begin{array}{l}\text { Ensures active paid user base generating content and } \\
\text { value in initial development and beyond }\end{array}$ & $\begin{array}{l}\text { Confusion in role and status of unpaid } \\
\text { volunteers; participation barrier }\end{array}$ \\
\hline $\begin{array}{l}\text { Member hierarchy } \\
\text { of rights }\end{array}$ & $\begin{array}{l}\text { Clearly defined roles for community members and } \\
\text { task fulfillment; ensures credibility/quality assurance }\end{array}$ & $\begin{array}{l}\text { Member asymmetries with task exclusion; limits } \\
\text { actions and slows production and allocation }\end{array}$ \\
\hline $\begin{array}{l}\text { Multiple channels } \\
\text { of communication }\end{array}$ & $\begin{array}{l}\text { Focused and time sensitive coordination between } \\
\text { active members; choice of platforms }\end{array}$ & $\begin{array}{l}\text { Fragmented and less accessible information for } \\
\text { less active members or new members }\end{array}$ \\
\hline Content focus & $\begin{array}{l}\text { Encourages specific visible types of contributions } \\
\text { limiting divergence/confusion }\end{array}$ & $\begin{array}{l}\text { Barrier to heterogeneous content production, } \\
\text { limiting diverse users and audience members }\end{array}$ \\
\hline $\begin{array}{l}\text { Explicit tasks / } \\
\text { formal processes }\end{array}$ & $\begin{array}{l}\text { Granular detailed information about required } \\
\text { task/skillset for resource allocation }\end{array}$ & $\begin{array}{l}\text { Excludes certain input and innovation; limits } \\
\text { contribution range }\end{array}$ \\
\hline
\end{tabular}

\section{Conclusions}

This paper presents a case study to theorize the impacts of a hybrid model of production on the development of a community and its resources. This study offers a number of contributions to research. Firstly, we characterize the open collaborative journalism model extending the boundaries of existing journalism models in the literature. Moreover, the paper presents empirical findings from a case study of this open collaborative journalism model and builds on the theory by Benkler [3] through the identification of a number of factors and their manifestations based on aspects of closed, hybrid, and open models of production, as well as accounting for the phases of a project's lifecycle. Finally, the paper describes a number of signals from these factors that should be considered when building a peer production community and deciding on specific open or closed characteristics. In terms of implications for practice, we present an analysis of a for-profit commercial organization and the impacts of combining both open and closed characteristics of production communities. The ability to include a hybrid model and leverage a community alongside paid professionals is possible, but a number of considerations need to be addressed when making decisions about community operations, technical infrastructures, and governance. Certain boundaries and restrictions benefit the efficiency of resource allocation, while others do the opposite. Given the limitations of a single case study, it is 
necessary to further study these factors and their signals and evaluate their manifestation in other contexts and peer production communities.

Acknowledgements This research is funded by the Lewis Charitable Foundation (USA) via the TOTO Research Project (2012-2020).

\section{References}

[1] Aitamurto, T., and S.C. Lewis, "Open innovation in digital journalism: Examining the impact of Open APIs at four news organizations", New Media \& Society 15(2), 2013, pp. 314-331.

[2] Arazy, O., O. Nov, and F. Ortega, "The [Wikipedia] World is not flat: on the Organizational Structure of Online production Communities", ECIS 2014, (2014).

[3] Benkler, Y., "Coase's Penguin, or, Linux and 'The Nature of the Firm'”, The Yale Law Journal 112(3), 2002, pp. 369 446.

[4] Bergquist, M., and J. Ljungberg, "The power of gifts: organizing social relationships in open source communities", Information Systems Journal 11(4), 2001, pp. 305-320.

[5] Borges, H., and M.T. Valente, "What's in a GitHub Star? Understanding Repository Starring Practices in a Social Coding Platform", Journal of Systems and Software 146, 2018, pp. 112-129.

[6] Bowman, S., and C. Willis, "We Media: How Audiences are Shaping the Future of News and Information", The Media Center, American Press Institute, 2003.

[7] de Carvalho Belochio, V., "O movimento Pro-Am e a prática da colaboração nos meios informativos:

especificidades do jornalismo colaborativo em redes digitais", Verso e Reverso 24(57), 2010, pp. 134-144. [8] Cozzolino, A., G. Verona, and F.T. Rothaermel, "Unpacking the Disruption Process: New Technology, Business Models, and Incumbent Adaptation", Journal of Management Studies 55(7), 2018, pp. 1166-1202.

[9] Dellermann, D., N. Lipusch, and P. Ebel, "Heading for new shores: Crowdsourcing for entrepreneurial opportunity creation", ECIS 2018, (2018).

[10] Fitzgerald, "The Transformation of Open Source Software", MIS Quarterly 30(3), 2006, pp. 587.

[11] Gasson, S., and M. Purcell, "Legitimate Peripheral Participation in Hybrid FOSS Community Innovation", HICSS 2018, 2018.

[12] Gaur, A., M. Osella, E. Ferro, and J. Hedman, “Open Innovation as Business Model Game-changer in the Public Sector", ECIS 2017, (2017).

[13] Hu, Y.-H., "News as conversation: The development and challenges of 'collaborative journalism' in Taiwan", Mass Communication Research(112), 2012, pp. 31-76. [14] Karlsson, M., A. Bergström, C. Clerwall, and K. Fast, "Participatory journalism - the (r)evolution that wasn't. Content and user behavior in Sweden 2007-2013", Journal of Computer-Mediated Comm. 20(3), 2015, pp. 295-311. [15] Lazo, C.M., and P.F. Batlle, "Information quality and trust: From traditional media to cybermedia", Studies in Systems, Decision and Control 154, 2019, pp. 185-206.
[16] Mare, A., “A complicated but symbiotic affair: The relationship between mainstream media and social media in the coverage of social protests in southern Africa", Ecquid Novi 34(1), 2013, pp. 83-98.

[17] McAllum, K., "Volunteers as Boundary Workers: Negotiating Tensions Between Volunteerism and Professionalism in Nonprofit Organizations", Management Communication Quarterly 32(4), 2018, pp. 534-564.

[18] McIntosh, S., "Collaboration, Consensus, and Conflict", Journalism Practice 2(2), 2008, pp. 197-211.

[19] Mindel, V., L. Mathiassen, and A. Rai, "The Sustainability of Polycentric Information Commons", MIS Quarterly 42(2), 2018, pp. 607-A14.

[20] Mor, N., and Z. Reich, "From 'Trust Me' to 'Show Me' Journalism”, Journalism Practice 12(9), 2018, pp. 10911108 .

[21] Nambisan, S., D. Siegel, and M. Kenney, "On open innovation, platforms, and entrepreneurship", Strategic Entrepreneurship Journal 12(3), 2018, pp. 354-368. [22] Nip, J.Y.M., "Exploring the Second Phase of Public Journalism", Journalism Studies 7(2), 2006, pp. 212-236. [23] Örebro, L.L., "Journalists and Politicians: a relationship requiring manoeuvring space", Journalism Studies 3(1), 2002, pp. 21-33.

[24] Pe-Than, E.P.P., L. Dabbish, and J.D. Herbsleb, "Collaborative Writing on GitHub: A Case Study of a Book Project”, ACM (2018), 305-308.

[25] Schirrmacher, N.-B., J. Ondrus, and T. Kude, "Launch Strategies of Digital Platforms: Platforms with Switching and Non-Switching Users", ECIS 2017, (2017), 17.

[26] Schlagwein, D., K. Conboy, J. Feller, J. Leimeister, and L. Morgan, “'Openness' with and without Information Technology: a framework and a brief history", Journal of Information Technology (Palgrave Macmillan) 32(4), 2017, pp. 297-305-305.

[27] Shu, K., A. Sliva, S. Wang, J. Tang, and H. Liu, "Fake News Detection on Social Media: A Data Mining

Perspective", SIGKDD Explor. Newsl. 19(1), 2017, pp. 22 36.

[28] Spangenberg, J., and N. Heise, "News from the Crowd: Grassroots and Collaborative Journalism in the Digital Age", Proceedings of the 23rd International Conference on World Wide Web, ACM (2014), 765-768.

[29] Valcarce, D.P., "Collaborative initiatives in cyberjournalism”, Opcion 32(Special Issue 12), 2016, pp. 134-147.

[30] Vobič, I., and P. Dahlgren, "Reconsidering Participatory Journalism in the Internet Age", Medijska istraživanja: znanstveno-stručni časopis za novinarstvo i medije 19(2), 2013, pp. 9-30.

[31] Yasseri, T., R. Sumi, A. Rung, A. Kornai, and J. Kertész, "Dynamics of Conflicts in Wikipedia", PLOS ONE 7(6), 2012, pp. e38869.

[32] Yin, R.K., Case study research design and methods, Thousand Oaks, Calif Sage Publications, 2009.

[33] Ziaie, P., and M. Imamovic, "Lifecycle-Based Evolution Of Features In Collaborative Open Production Communities: The Case Of Wikipedia", ECIS 2013, (2013). 